\title{
Cirrus clouds triggered by radiation, a multiscale phenomenon
}

\author{
F. Fusina and P. Spichtinger \\ ETH Zurich, Institute for Atmospheric and Climatic Science, Universitaetstrasse 16, 8092 Zurich, Switzerland
}

Received: 22 October 2009 - Published in Atmos. Chem. Phys. Discuss.: 18 January 2010

Revised: 5 May 2010 - Accepted: 17 May 2010 - Published: 11 June 2010

\begin{abstract}
In this study, the influence of radiative cooling and small eddies on cirrus formation is investigated. For this purpose the non-hydrostatic, anelastic model EULAG is used with a recently developed and validated ice microphysics scheme (Spichtinger and Gierens, 2009a). Additionally, we implemented a fast radiative transfer code ( $\mathrm{Fu}$ et al., 1998). Using idealized profiles with high ice supersaturations up to $144 \%$ and weakly stable stratifications with Brunt-Vaisala frequencies down to $0.0018 \mathrm{~s}^{-1}$ within a supersaturated layer, the influence of radiation on the formation of cirrus clouds is remarkable. Due to the radiative cooling at the top of the ice supersaturated layer with cooling rates down to $-3.5 \mathrm{~K} / \mathrm{d}$, the stability inside the ice supersaturated layer decreases with time. During destabilization, small eddies induced by Gaussian temperature fluctuations start to grow and trigger first nucleation. These first nucleation events then induce the growth of convective cells due to the radiative destabilization. The effects of increasing the local relative humidity by cooling due to radiation and adiabatic lifting lead to the formation of a cirrus cloud with IWC up to $33 \mathrm{mg} / \mathrm{m}^{3}$ and mean optical depths up to 0.36 . In a more stable environment, radiative cooling is not strong enough to destabilize the supersaturated layer within $8 \mathrm{~h}$; no nucleation occurs in this case.

Overall triggering of cirrus clouds via radiation works only if the supersaturated layer is destabilized by radiative cooling such that small eddies can grow in amplitude and finally initialize ice nucleation. Both processes on different scales, small-scale eddies and large-scale radiative cooling are necessary.
\end{abstract}

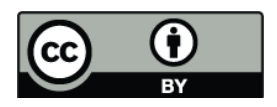

Correspondence to: F. Fusina (fabian.fusina@env.ethz.ch)

\section{Introduction}

The existence of cloud-free air masses that are supersaturated with respect to ice in the upper troposphere or lowermost stratosphere has long been known. More than 60 years ago, Glückauf (1945) obtained values of relative humidity with respect to ice (RHi) up to $160 \%$ over Southern England. The fact that high ice supersaturations can occur in the upper troposphere has been neglected for many years and has often been termed erroneous. During the last two decades the existence of supersaturated airmasses has been proven by many measurements using a variety of different measurement techniques (e.g. Jensen et al., 1998; Vay et al., 2000; Ovarlez et al., 2000; Krämer et al., 2009). These measurements are consistent with theoretical considerations, that ice crystals form at very high supersaturations, where the exact freezing threshold depends on the nucleation mechanism (homogeneous freezing of solution droplets or heterogeneous nucleation, see e.g. Koop et al., 2000; De Mott et al., 2003 , respectively). For homogeneous nucleation, which is probably the dominant mechanism for ice crystal formation at low temperatures $\left(T<-38^{\circ} \mathrm{C}\right)$ relative humidities in the range 140 to $170 \% \mathrm{RHi}$, depending on temperature (Koop et al., 2000), are required.

The properties and global distributions of ice supersaturated regions (ISSRs) have been determined over recent years (e.g. Spichtinger et al., 2003a,b; Gettelman et al., 2006). They occur 20 to $30 \%$ of the time in cloud free air masses in the upper troposphere over the North Atlantic. The large horizontal extent of ISSRs, with mean path lengths of about $150 \mathrm{~km}$, and in some rare cases of a few thousand kilometers (Gierens and Spichtinger, 2000) means that there is a substantial amount of cloud free air masses with enhanced water vapor content. However, only a few parametrizations exist that correctly (i.e. physically) describe the formation of cirrus clouds (from ISSRs) driven by synoptic scale dynamics

Published by Copernicus Publications on behalf of the European Geosciences Union. 


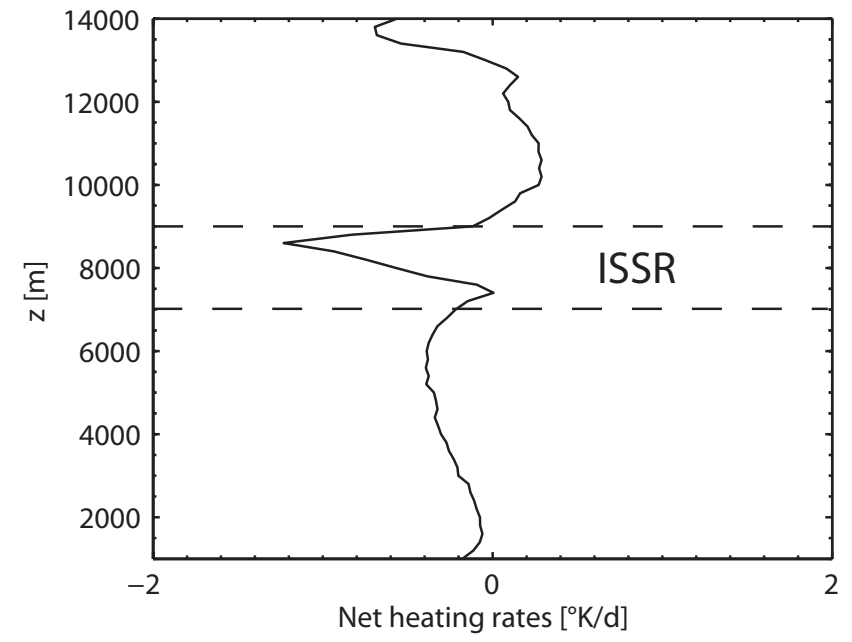

Fig. 1. Heating-rates [K/d] of an ISSR with $\mathrm{RHi}=130 \%$ due to emission and absorption of radiation.

(CAM3, see Lin et al., 2007; ECHAM5, see Kärcher and Lohmann, 2002). The impact of meso- and small-scale motions is not explicitly included, although some approximations are used to obtain meso-scale motions (Kärcher and Lohmann, 2002).

The radiative impact of ISSRs (with RHi up to 130\%) has been investigated by Fusina et al. (2007). These regions of enhanced water vapor can reduce the total outgoing longwave radiation by more than $1 \mathrm{~W} / \mathrm{m}^{2}$ and imply a significant cooling at their upper boundary (i.e. due to thermal emission).

In a stably stratified atmosphere, these diabatic heating rates are too small to significantly influence the local dynamics. But if potential stability of the environment is weak or neutral, radiative cooling can decrease the Brunt-Vaisala frequency to a critical value. This finally leads to a change (increase) of the extent and amplitude of preexisting small scale motions. The combination of the locally amplified vertical velocity and the radiative cooling can trigger the first nucleation. Regions with weak stratification (i.e. small vertical gradients of potential temperature) have been observed in the upper troposphere, using radiosonde data obtained over the meteorological observatory in Lindenberg, Germany. In these regions dynamical instabilities could also occur: The Miles theorem describes that a stable atmosphere is given by a Richardson number $R i>0.25$,

$R i=\frac{N^{2}}{\left(\frac{\partial u}{\partial z}\right)^{2}}$, using $N^{2}=\frac{g}{\theta} \frac{\partial \theta}{\partial z}$

where $N$ denotes the Brunt-Vaisala frequency. Moderate and strong windshears are often observed in the upper troposphere, as described by Birner (2006).
In this study, we investigate the possibility of cirrus cloud formation due to radiative cooling in weakly stable layers within the upper troposphere. Sensitivity studies are carried out for the most important initial parameters such as potential stability, windshear and RHi within the ISSR. The main purpose is to investigate the sensitivity to environmental conditions, for which radiative cooling (a large scale process) at the top of an ISSR can destabilize the stratification. During the destabilization, the amplitude of preexisting small scale eddies increase and trigger cloud formation. Only the superposition of effects on different scales (i.e. large-scale radiative cooling and small scale motions) can finally lead to cirrus formation. The main properties of the formed cirrus clouds are investigated, such as ice water content (IWC), ice crystal number density $(N)$, cloud life time and their impact on the radiation. For this purpose, the non-hydrostatic anelastic model EuLag (Eulerian, semi-Lagrangian Model) is used (e.g. Prusa et al., 2008), using a two stream radiative transfer code (Fu, 1996; Fu et al., 1998) and an ice microphysics scheme (Spichtinger and Gierens, 2009a).

The paper is organized as follows: In the next section, the model is described briefly. In Sect. 3 we define the experimental setup for the reference simulations. In Sect. 4, results of the reference and sensitivity simulations are presented. We end with discussions and conclusions.

\section{Model description}

As a basic dynamical model, the anelastic nonhydrostatic model EULAG is used (see Prusa et al., 2008). The dry anelastic equations solved in the model are presented in Smolarkiewicz and Margolin (1997).

\subsection{Ice physics}

A recently developed bulk ice microphysic scheme is used, which can treat an arbitrary number of ice classes. These ice classes are distinguished by their formation mechanism (e.g. heterogeneously vs. homogeneously formed ice). The following processes for cold cirrus clouds are parameterized: nucleation (homogeneous), deposition (growth, evaporation) and sedimentation (Spichtinger and Gierens, 2009a). It provides a consistent double moment scheme with terminal velocities for ice number and mass concentration. Aggregation is not yet implemented in the microphysics scheme. However, aggregation is of less importance for the cold temperature regime $\left(T<-38^{\circ} \mathrm{C}\right)$ and/or for moderate vertical velocities (Kajikawa and Heymsfield, 1989).

For the parametrization of homogeneous freezing of aqueous solution droplets, sulfuric acid solution droplets are assumed as a background aerosol, using a lognormal distribution for the $\mathrm{H}_{2} \mathrm{SO}_{4}$ droplet size (geometric standard deviation $\sigma_{\mathrm{r}}=1.4$, geometric mode radius $r_{\mathrm{m}}=25 \mathrm{~nm}$, total number concentration $300 \mathrm{~cm}^{-3}$ ). The freezing rates are calculated 

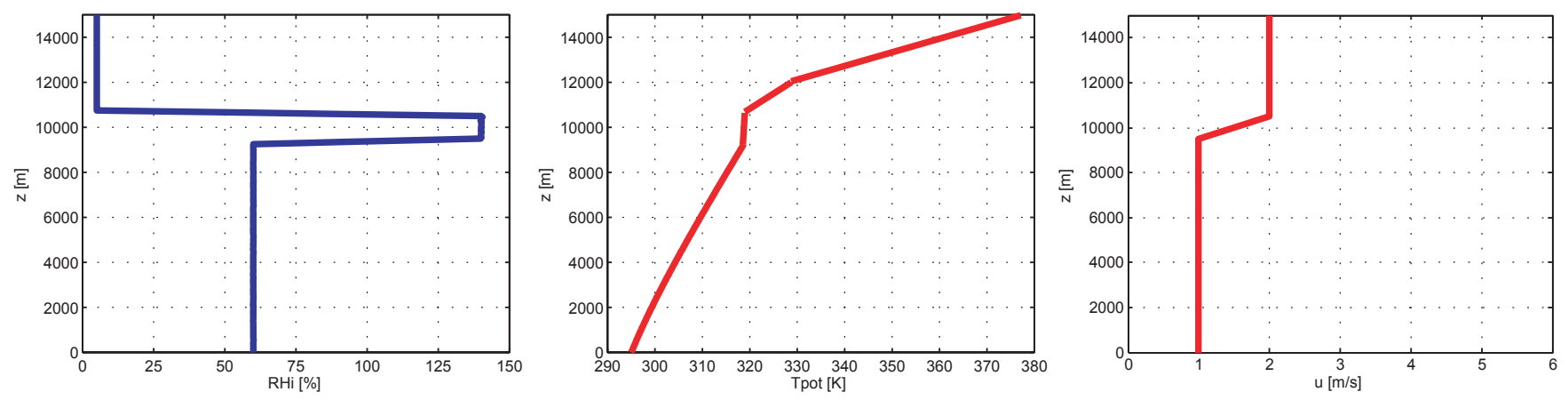

Fig. 2. Vertical profiles used for the reference simulation. Left: RHi profile; middle: potential temperature profile; right: horizontal velocity profile.

using a temperature based parametrization, based on water activity (see Koop et al., 2000). We use a modified Koenig ansatz (Koenig, 1971) to parameterize the diffusional growth or evaporation for small ice crystals, including corrections for the kinetic growth regime and ventilation respectively. For all simulations in this study, only homogeneous nucleation is taken into account. For details of the model, the reader is referred to Spichtinger and Gierens (2009a).

\subsection{Radiation transfer model}

A two stream radiative transfer code, i.e. a representation of forward and backward streams, has been implemented into the EuLag model. It contains 6 bands in the solar and 12 bands in the thermal infrared regime. For a detailed description, the reader is referred to $\mathrm{Fu}$ (1996) for the shortwave and to Fu et al. (1998) for the longwave parametrizations, respectively.

The required parameters for ice microphysics are ice water content (IWC) and effective radius, which is derived following Slingo (1989), Dobbie et al. (1999) and Fu (1996). In the microphysical model ice crystals are assumed to be small hexagonal columns. The ice crystal size is lognormally distributed with a geometric standard deviation of $\sigma_{\mathrm{L}}=1.5$. The effective radius is calculated as described in Fusina et al. (2007) under the assumption of randomly oriented columns (Ebert and Curry, 1992).

The radiative transfer code uses following constant trace gas concentrations: $\mathrm{CO}_{2}: 330$ ppmv; $\mathrm{CH}_{4}: 1.6$ ppmv; $\mathrm{N}_{2} \mathrm{O}$ : $0.28 \mathrm{ppmv}$, respectively (default values of the radiative transfer model). The ozone profile depends on altitude, including the stratospheric ozone layer. The model domain of the radiative transfer code has a maximum altitude of $L_{z r}=50 \mathrm{~km}$, which is not necessarily equivalent to the top level of the EULAG model $\left(L_{z}\right)$. The vertical resolution within the EULAG model domain is set by the model setup. If $L_{z r}>L_{z}$ (this is the case for our simulations), the vertical resolution of the additional layers exceeding the EULAG model domain is set to $1 \mathrm{~km}$, the water vapor mixing ratio is set to $q_{\mathrm{v}}=10^{-11} \mathrm{~kg} / \mathrm{kg}$, the pressure profile is interpolated using the US standard atmosphere; the temperature profile is built using a constant lapse rate up to a final temperature of $T(50 \mathrm{~km})=275 \mathrm{~K}$ (according to the US standard atmosphere, COESA, 1976). The solar zenith angle is set to $60^{\circ}$ and the solar surface albedo is 0.3 . The infrared surface emissivity is assumed to be 1 .

\section{Experimental setup}

For the simulations, an idealized framework is used, including a 2-D model domain with a horizontal extent of $L_{x}=12.8 \mathrm{~km}$ and a vertical extent of $L_{z}=15 \mathrm{~km}$ for dynamics and ice microphysics, respectively. An ISSR is placed between $l b=9500 \mathrm{~m}$ and $u b=10500 \mathrm{~m}$ with a constant relative humidity over ice of $140 \%$, which fully occupies the whole horizontal extent of this layer. RHi below and above the ISSR is set to $60 \%$ and 5\%, respectively (see Fig. 2, left panel). Using a grid resolution of $d x=100 \mathrm{~m}$ and $d z=50 \mathrm{~m}$, in the horizontal and the vertical, respectively, the domain is discretized with $n x \times n z=128 \times 301$ grid points.

A constant-stratification ambient profile of potential temperature, as described by Clark and Farley (1984), is used with a surface temperature $T=293.15 \mathrm{~K}$ and a Brunt-Vaisala frequency $N=0.0094 \mathrm{~s}^{-1}$. Within the layer between $9250 \mathrm{~m}$ and $10750 \mathrm{~m}$ altitude, the stability of the stratification is decreased to a constant vertical gradient of the potential temperature of $\partial \theta / \partial z=0.4 \mathrm{~K} / \mathrm{km}$ (which corresponds to a Brunt-Vaisala frequency $N=0.0035 \mathrm{~s}^{-1}$ ). The tropopause is placed at an altitude of $12000 \mathrm{~m}$ (see Fig. 2 middle). The stability above the tropopause is set to $N=0.02 \mathrm{~s}^{-1}$. The profile of the horizontal velocity contains a constant wind below and above and a weak windshear of $\partial u / \partial z=1 \times 10^{-3} \mathrm{~s}^{-1}$ (for the reference case) within the ISSR (Fig. 2, right panel): 
$u(z)=\left\{\begin{array}{lll}1 & \text { for } & 0 \leq z<l b \\ 1+d u_{z} \cdot(z-l b) & \text { for } & l b \leq z \leq u b \\ 1+d u_{z} \cdot(u b-l b) & \text { for } & u b<z\end{array}\right.$

The initial potential temperature field is distributed by a Gaussian noise with standard deviation $\sigma_{T}=0.01 \mathrm{~K}$. All simulations run for a total time of $8 \mathrm{~h}$ with $1 \mathrm{~s}$ increments for the dynamics, optional $0.1 \mathrm{~s}$ increments for the ice physics in case of homogeneous nucleation and $10 \mathrm{~s}$ increments for the radiation, respectively. We assume a calm troposphere, i.e. no vertical wind in our small 2-D domain.

\section{Results}

\subsection{Reference case}

At the beginning of the reference case simulation, only radiative processes (emission and absorption of LW radiation) can change dynamical and microphysical properties in the domain. The obtained heating rates (see Fig. 3) have an impact on two major characteristics within the ISSR. First, the temperature decrease (strongest at the top) tends to increase RHi by $\sim+1 \%$ per hour (see Fig. $4 d$ ). Second, the stability of the stratification decreases with time, reaching its lowest neutral/unstable state at $t=200 \mathrm{~min}$ (see Fig. 4a), where the first unstable grid cells (i.e. with a negative squared BruntVaisala frequency) occur at $t=150 \mathrm{~min}$. Within this first $200 \mathrm{~min}$, small eddies (induced by initial temperature fluctuations) grow due to the destabilization and start to lift up air parcels, temporally increasing their RHi. Patterns within the vertically averaged turbulent kinetic energy enhance the formation and growth of these small cells. However, the vertical velocities do not increase significantly before the stratification becomes unstable, but the amplitude of the temperature deviations increases slightly.

After $t=200 \mathrm{~min}$, the eddies start to grow rapidly in size (favored by the unstable environment) and therefore, the first air parcels reach the threshold of homogeneous nucleation of $156 \%$ (see Fig. 4d). This effect happens only in several small isolated cells, surrounded by downwelling regions. Latent heat release due to the growth of the ice crystals amplifies the motions inside the ISSR, increasing the vertical velocity from its preliminary $w_{\max }= \pm 0.03 \mathrm{~m} / \mathrm{s}$ up to $w_{\max }= \pm 0.5 \mathrm{~m} / \mathrm{s}$, forming convective cells. The formed cirrus cloud is persistent over the rest of the simulation time, containing ice crystal number concentrations up to $N=300 \mathrm{~L}^{-1}$ and a maximum mean ice water path of $\overline{\mathrm{IWP}}=2.95 \times 10^{-3} \mathrm{~kg} / \mathrm{m}^{2}$ (averaged over all columns). The peak with the highest ice water content corresponds to a local maximum of the vertical velocity. The whole time evolution for IWP is showed in Fig. 4c.

At the time of maximum IWP, an optical depth of $\bar{\tau}=0.1$ is derived. $\bar{\tau}$ is averaged over all columns, observing a peakvalue of $\tau=0.36$, which is significantly higher than the mean

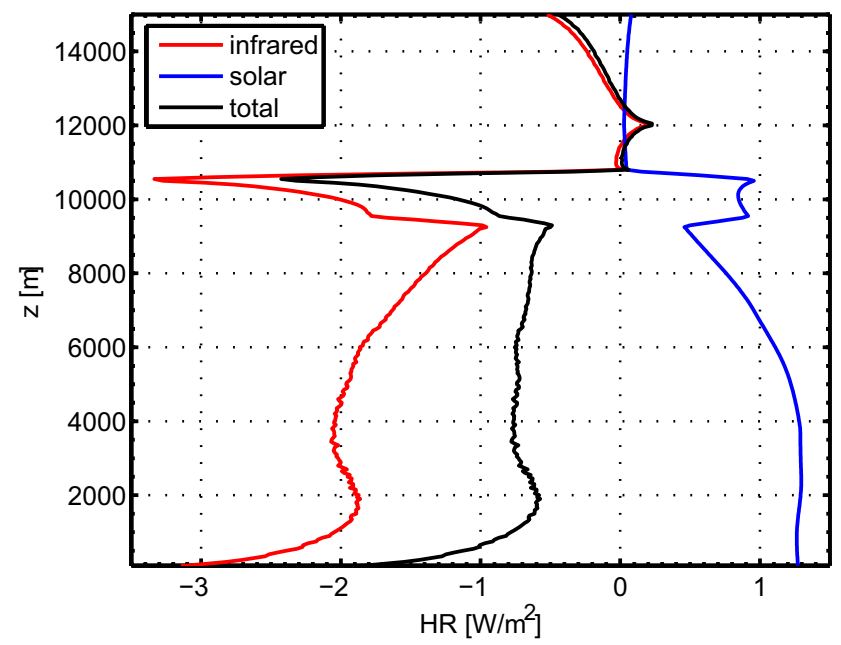

Fig. 3. Vertical radiative heating rates (split into solar, infrared and total) at the initial time step, containing an ISSR with maximum RHi of $140 \%$.

value due to the patchiness of the cloud. Due to the high supersaturation inside the layer, the formed ice crystals grow rapidly to larger sizes and start to sediment. During the downward motion, they continue to grow and deplete water vapor, reducing the RHi in the lower part of the ISSR. In the downwelling regions, some entrainment of very dry air from above the ISSR can be observed, making the 2-D field of RHi more patchy than before. Within the upper part of the ISSR, at the top of the upwelling regions, the RHi remains at the homogeneous freezing threshold for a longer time, continuously forming new ice crystals (Fig. 5, $t=360 \mathrm{~min}$ ).

\subsection{Variation of potential stability}

For sensitivity tests, the initial vertical gradient of the potential temperature $\theta$ is changed within the ISSR. For a small wind shear, as used in the reference case and in this set of sensitivity simulations, this value represents the stability because of high Richardson numbers. Cases with stronger wind shear will be discussed in the next section. A set of value is chosen as: $\partial \theta / \partial z=0.1 / 0.2 / 0.3 / 0.4 / 0.5 / 0.6 / 0.8 \mathrm{~K} / \mathrm{km}$ (corresponding to Brunt-Vaisala frequencies $N=$ 0.0018/0.0025/0.003/0.0035/0.0039/0.0043/0.005 $\mathrm{s}^{-1}$, respectively). These values have been compared with radiosonde records obtained from routine measurements over the meteorological observatory Lindenberg, Germany (see e.g. Spichtinger et al., 2003a). The dataset covers the time period from 1 February 2000 to 30 April 2001 with measurements every 6 h (i.e. 00:00, 06:00, 12:00, 18:00 UTC). $14.7 \%$ of all profiles show a layer of at least $500 \mathrm{~m}$ thickness, containing a potential stability between 0.1 and $0.8 \mathrm{~K} / \mathrm{km}$ ( $5 \%$ for stabilities lower than $0.4 \mathrm{~K} / \mathrm{km}$; reference case). $3.26 \%$ of all profiles contain the same stability, but within a 

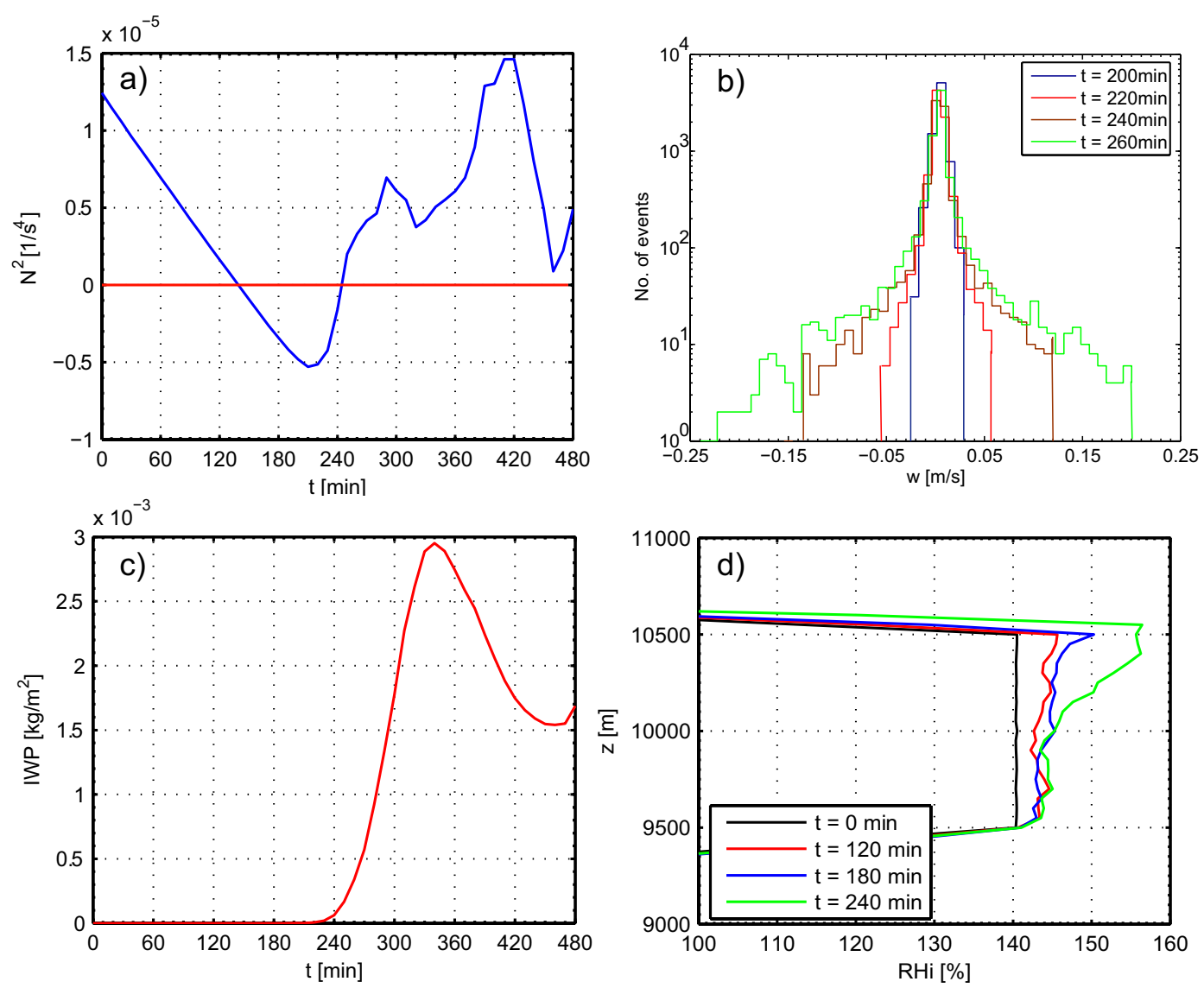

Fig. 4. (a) Time evolution of horizontal mean of the squared Brunt-Vaisala frequency at $z=10500 \mathrm{~m}$ (altitude of maximum cooling); (b) Histogram: vertical velocity for 4 different timesteps (200/220/240/260 min); (c) Time evolution of mean ice water path (IWP); (d) Maximum RHi for 4 different timesteps $(0 / 120 / 180 / 240 \mathrm{~min})$.

layer of at least $1 \mathrm{~km}$ thickness $(0.64 \%$ for stabilities lower than $0.4 \mathrm{~K} / \mathrm{km}$ ). These cases are filtered for temperatures lower than $235 \mathrm{~K}$ for comparison in potential cirrus regions. It follows that the values used in this sensitivity study are in the range of atmospheric relevance.

All cases in this sensitivity simulation fulfill the Miles theorem for shear stability (i.e. $R i>0.25$ ). All other simulation parameters are equal to the reference case.

When we reduce the vertical gradient of the potential temperature of the reference case $(0.4 \mathrm{~K} / \mathrm{km})$ to $\partial \theta / \partial z=$ $0.2 \mathrm{~K} / \mathrm{km}$, the maximum obtained amount of $\overline{I W P}$ increases from $\overline{\mathrm{IWP}}=3 \times 10^{-3} \mathrm{~kg} / \mathrm{m}^{2}$ to $\overline{\mathrm{IWP}}=6.8 \times 10^{-3} \mathrm{~kg} / \mathrm{m}^{2}$. This peak value appears $100 \mathrm{~min}$ earlier than in the reference case and corresponds to the moment of maximum kinetic energy within the ISSR (i.e. the vertical wind speeds are strongest; see Fig. 6b). One can conclude that in simulations with a lower stability inside the ISSR, nucleation occurs earlier than in the reference case due to two reasons. First, the amplitude of the temperature variation inside the small eddies is larger due to the lower stability. Second, and more important, by the destabilization of the layer due to ra- diation is faster, starting at lower Brunt-Vaisala frequencies. The obtained $\overline{\text { IWP }}$ is higher for cases with weaker initial stabilities (Fig. 6a). The largest $\overline{\mathrm{IWP}}=8.9 \times 10^{-3} \mathrm{~kg} / \mathrm{m}^{2}$ (with a maximum value of IWC $=33 \mathrm{mg} / \mathrm{m}^{3}$ ) can be observed for the simulation with the weakest initial potential stability, $170 \mathrm{~min}$ after initialization. The main reason for the higher IWP are the higher vertical velocities obtained in the simulations with weaker initial stability, resulting in higher ice crystal amounts (Fig. 7). In the simulation with the weakest stability $(0.1 \mathrm{~K} / \mathrm{km})$, vertical updrafts of up to $w=1.6 \mathrm{~m} / \mathrm{s}$ are observed in some isolated cells. If the initial stability is reduced further, then convective cells can be generated due to the initial temperature perturbations and the role of the radiation in the cloud building process is no longer dominant (i.e. the superposition of these two effects, radiation and small eddies, is no longer required). For higher initial stabilities the destabilization event takes more time. For all simulations with a stronger stability than the reference case, the simulation time of $480 \mathrm{~min}$ is not sufficient to deplete the whole supersaturation inside the layer. In these cases, layerclouds are formed in the upper part of the ISSR. If the initial 

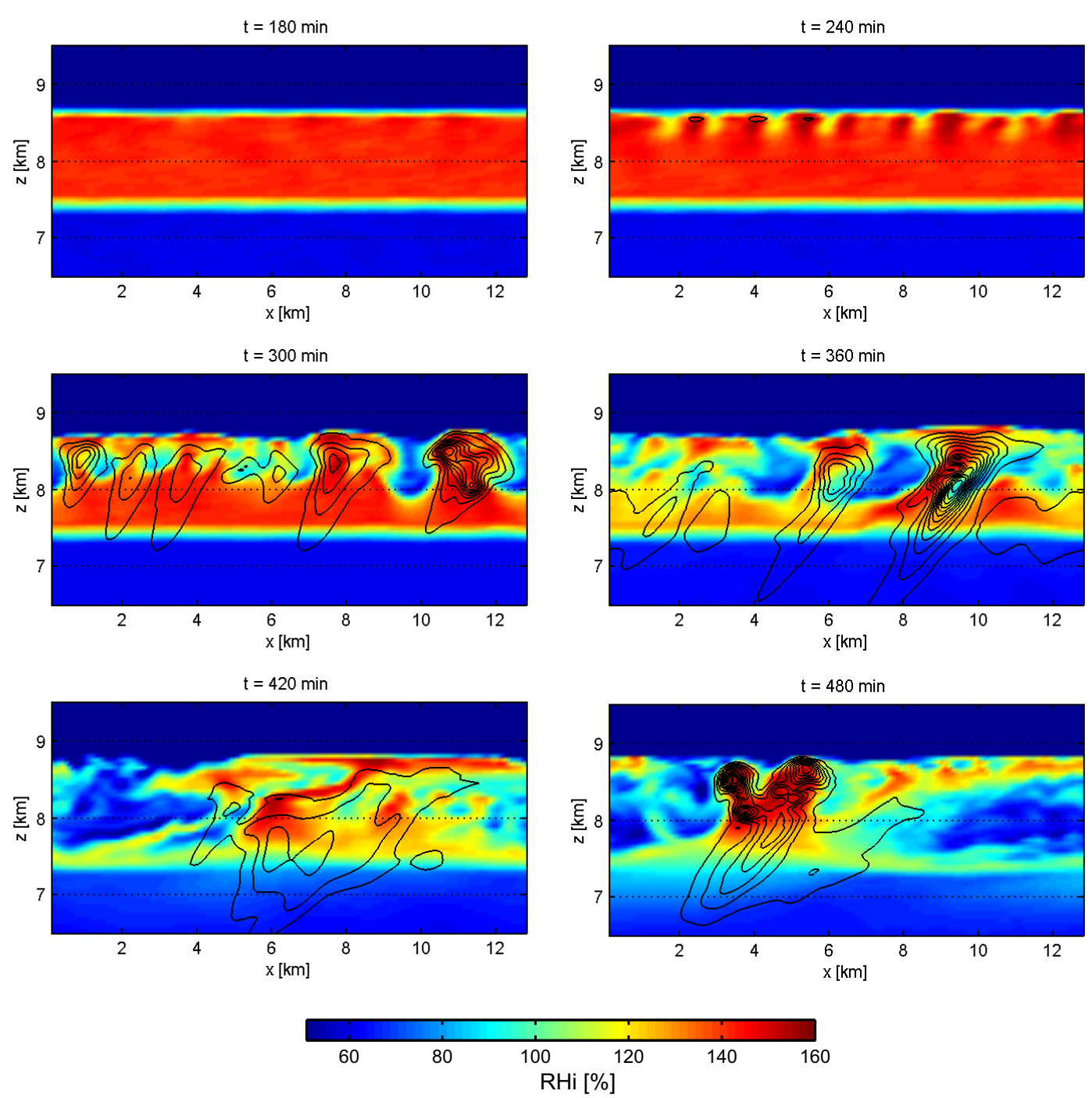

Fig. 5. Cirrus cloud formation in the reference simulation - Colors indicate RHi in $\%$; Contour lines represent IWC $\left[10^{-6} \mathrm{~kg} / \mathrm{m}^{3}\right]$ increments. Time evolution: 1. Destabilization at ISSR top, first nucleation. 2. Developement of the cloud/convective cells. 3. Entrainment.

stability exceeds the threshold of $0.8 \mathrm{~K} / \mathrm{km}$, no nucleation occurs within the $8 \mathrm{~h}$ simulation time.

\subsection{Variation of wind shear}

In a second set of sensitivity simulations, the impact of different strengths of wind shear is determined while the thermal stratification is set to the reference value of $\partial \theta / \partial z=$ $0.4 \mathrm{~K} / \mathrm{km}$. We use values of $\partial u / \partial z=0 / 1 / 2 / 4 / 6 / 8 \times$ $10^{-3} \mathrm{~s}^{-1}$ in the altitude range $9500 \leq z \leq 10500 \mathrm{~m}$ (see Fig. 8a). The chosen values are weak, but in the range of observations in the upper troposphere (see, e.g., the statistics presented by Birner, 2006). For the strongest wind shear $\partial u / \partial z=8 \times 10^{-3} \mathrm{~s}^{-1}$, the initial Richardson Number $R i=0.19<0.25$ is below the threshold for shear instability. In this case, we expect the formation of Kelvin-Helmholtz instabilities. Values of wind shear above this threshold are not of interest for this study, because the mixing effect of shear instability would superimpose with the destabilization effect of radiative cooling in an unpredictable way. All other simulation parameters are equal to the reference case.

For this set of sensitivity simulations, the highest $\overline{\text { IWP }}=$ $4.15 \times 10^{-3} \mathrm{~kg} / \mathrm{m}^{2}$ was observed for zero wind shear. In this scenario, the formation and evolution of the isolated convective cells is not affected by wind shear, so the cells have a larger vertical extent than in the cases with windshear. The statistics in Birner (2006) show that for the mid-latitudes, wind shear free scenarios are very unlikely at cirrus altitudes. Increasing the wind shear to $\partial u / \partial z=2 \times 10^{-3} \mathrm{~s}^{-1}$ reduces the vertical extent of the upwelling regions and the vertical updraft velocity inside. The cells start to tilt with height. 

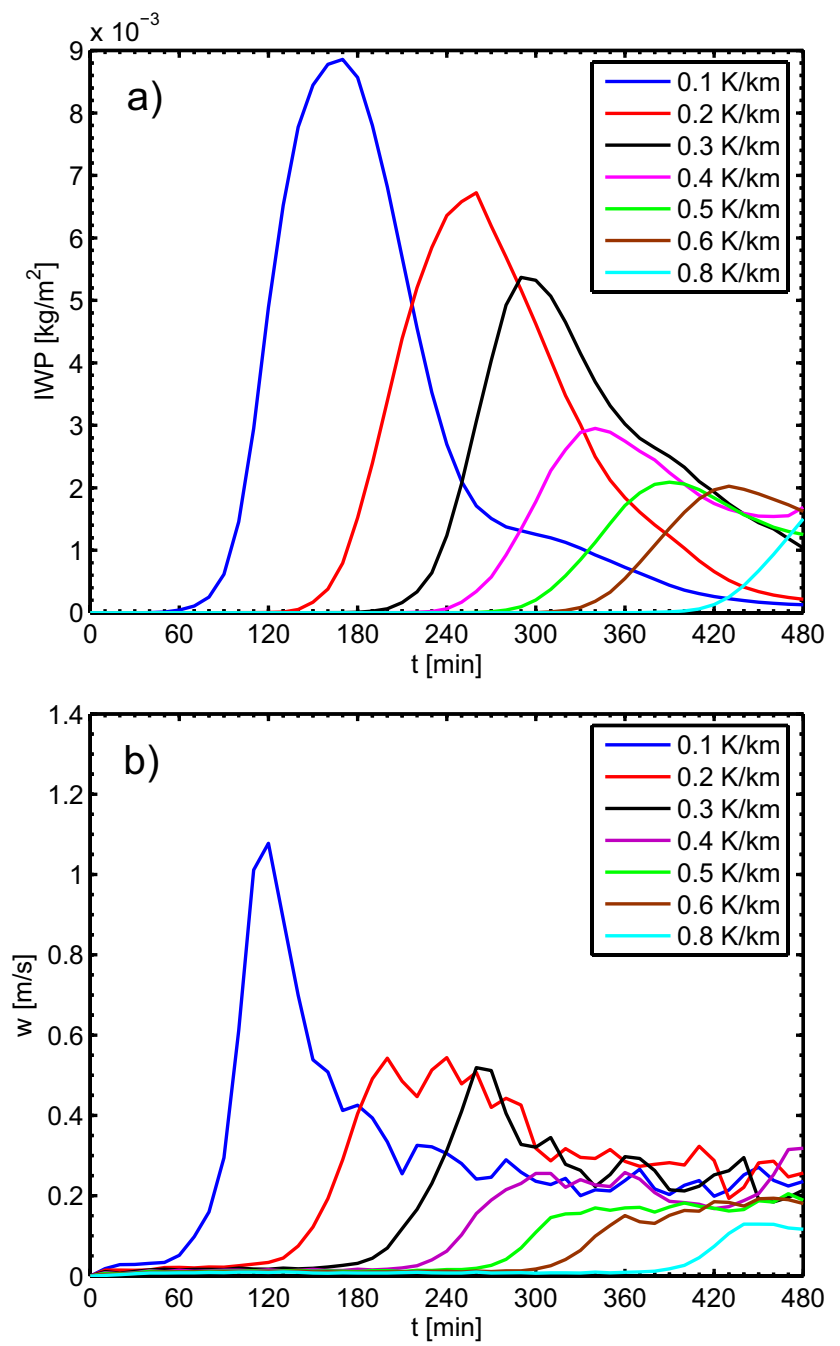

Fig. 6. (a) $\overline{\mathrm{IWP}}$ (averaged over all columns) for thermal stratification $\partial \theta / \partial z=0.1$ to $0.8 \mathrm{~K} / \mathrm{km}$. The purple line represents the reference case; (b) median of the maximum $5 \%$ vertical wind speeds within the ISSR for thermal stratification $\partial \theta / \partial z=0.1$ to $0.8 \mathrm{~K} / \mathrm{km}$. The purple line represents the reference case.

Due to the increased mixing inside the ISSR, fewer regions with RHi close to the homogeneous threshold are observed. This leads to reduced nucleation, whereby the number of ice crystals $N$ decreases. Increasing the wind shear more will amplify these further effects, leading to lower IWPs (see Fig. 8b). For windshears of $\partial u / \partial z \geq 4 \times 10^{-3} \mathrm{~s}^{-1}$, shear instability is generated with time. This leads to more turbulent motions inside the ISSR and results in stronger vertical velocities followed by an increased homogeneous nucleation rate. For the case with the highest windshear of $\partial u / \partial z \geq 8 \times 10^{-3} \mathrm{~s}^{-1}$, a pronounced Kelvin-Helmholtz instability develops after $t=440 \mathrm{~min}$, containing vertical updraft velocities of $w>2 \mathrm{~m} / \mathrm{s}$. The cirrus clouds formed by turbulence due to shear instabilities appear even, when the ra-
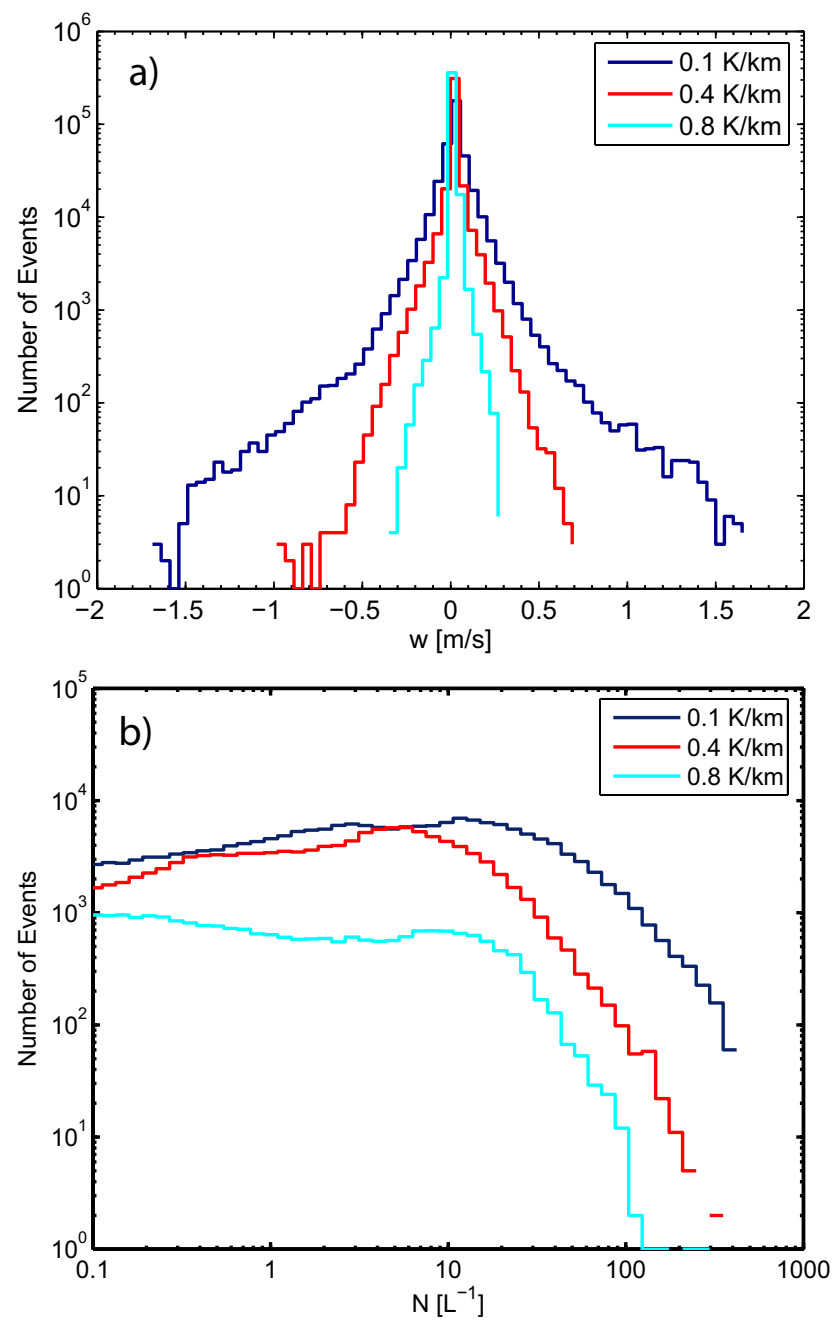

Fig. 7. (a) Histogram of vertical velocity for all time steps (for 3 different thermal stratifications $\partial \theta / \partial z=0.1 / 0.4 / 0.8 \mathrm{~K} / \mathrm{km}$ ). The red line represents the reference case; (b) Histogram of number concentration for all time steps (for 3 different thermal stratifications $\partial \theta / \partial z=0.1 / 0.4 / 0.8 \mathrm{~K} / \mathrm{km}$. The red line represents the reference case.)

diation code is disabled. For this reason, they are not of interest for this study. It can be concluded that, after the destabilization of the stratification due to radiative cooling, isolated eddies are a key feature of cirrus clouds triggered by radiation, supported by the latent heat release after the first nucleation event. Their evolution and persistence is suppressed by stronger wind shears. Wind shear can also block the destabilization of the layer with the highest radiative cooling rate, by mixing it with the surrounding air. However, this happens only for values close to the threshold for shear instability $(R i \leq 0.25)$. 

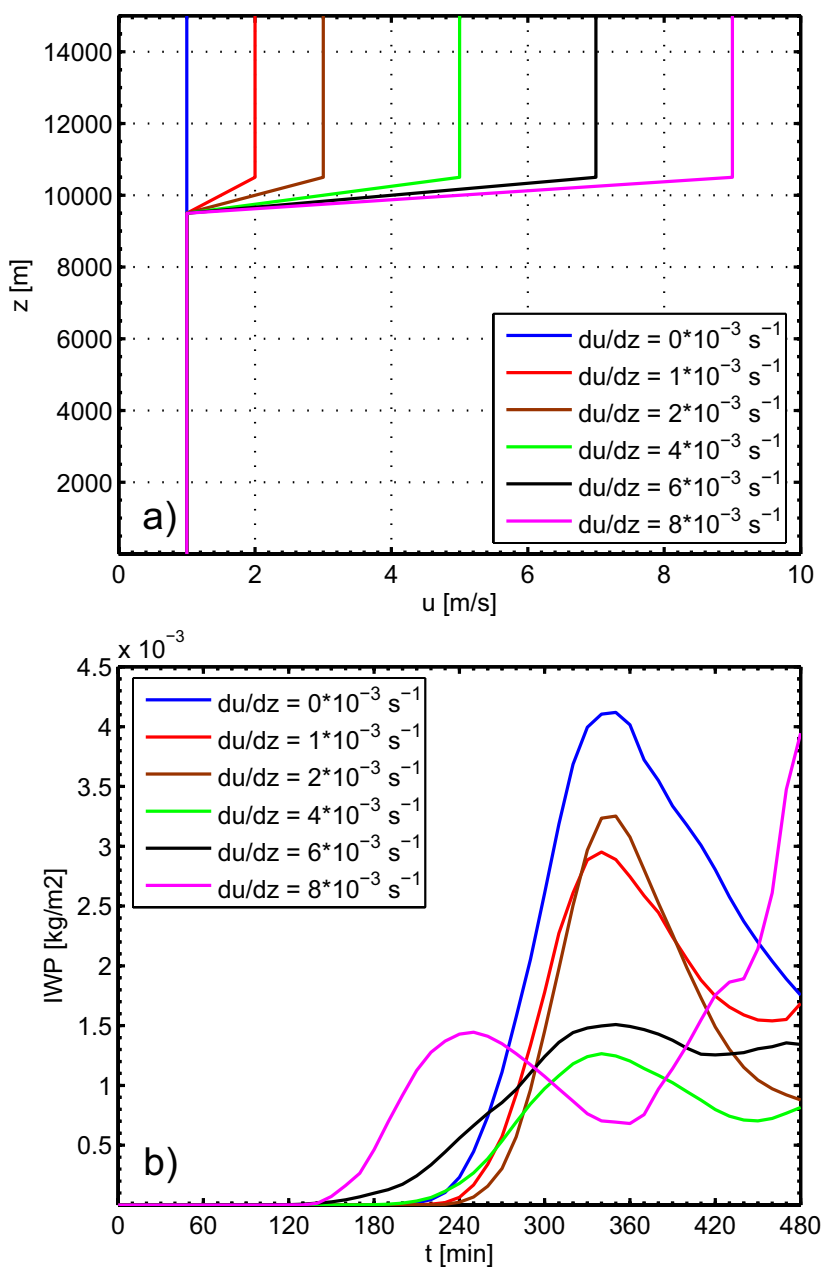

Fig. 8. (a) 6 vertical profiles for horizontal wind speed containing different wind shears within the ISSR. The red line represents the reference case; (b) $\overline{\mathrm{IWP}}$ (averaged over all columns) for windshears from 0 to $8 \times 10^{-3} s^{-1}$.

\subsection{Variation of RHi}

A third set of sensitivity simulations uses different amounts of water vapor inside the ISSR. By increasing the RHi, the distance to the homogeneous freezing threshold is decreased, so earlier nucleation can be expected. Decreasing the RHi leads to the opposite effect. The values used for RHi are 132/136/140/144\%, respectively. Wind shear and thermal stability are set to the values in the reference case $\left(\partial u / \partial z=10^{-3} \mathrm{~s}^{-1}, N=0.0035 \mathrm{~s}^{-1}\right)$.

For simulations with a maximum RHi lower than in the reference case (i.e. $<140 \%$ ), it takes more time to reach the homogeneous freezing threshold (due to cooling from emission and adiabatic lifting). On the other hand, the radiative cooling inside the ISSR is a function of the RHi (i.e. the water vapor mixing ratio) as discussed in Fusina et al. (2007). Thus, for lower RHi values at the same temperature, the cool-

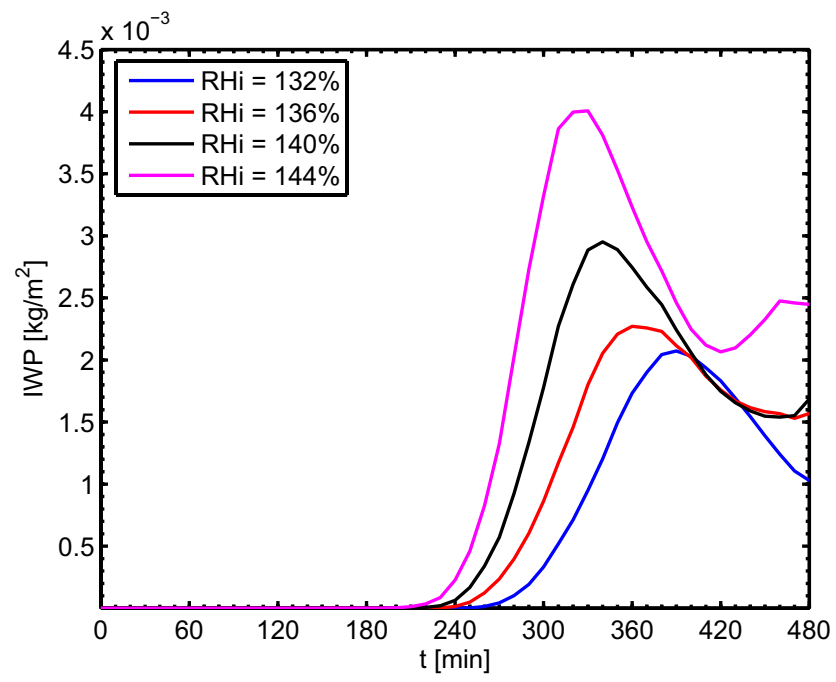

Fig. 9. Mean ice water path $\overline{\mathrm{IWP}}$ (averaged over all columns) of simulations using different initial values for RHi inside the ISSR ( $\mathrm{RHi}=132$ to $144 \%$ ). The black line represents the reference case.

ing rates decrease. This results in a slower destabilization of the upper part of the ISSR. The differences between the updraft velocities are small, no significant change in the numbers of ice crystals can be observed between the different simulations. It follows that the enhanced water-vapor content increases the size of the ice crystals but not their number concentration. This can modulate the cirrus life time, as larger crystals fall faster down to subsaturated regions and sublimate.

For the simulation with $\mathrm{RHi}=144 \%$, the nucleation starts 15 min earlier than in the reference case, obtaining a maximum IWP that is $30 \%$ higher. A comparison of the IWP between the different sensitivity simulations is given in Fig. 9. In the simulations with $\mathrm{RHi}=136 / 140 / 144 \%$, a second nucleation peak at the end of the simulation can be observed. This nucleation event is possibly triggered by the latent heat release during the earlier ice crystal forming, superimposed with destabilization due to radiative cooling. If the initial RHi is reduced to less than $132 \%$, the cooling will again get weaker and no destabilization occurs (i.e. formation of an updraft) and for this reason, no nucleation can be observed during the simulation time of $8 \mathrm{~h}$. If the initial RHi is increased to $150 \%$ or more, the small scale motions due to the initial temperature fluctuations are strong enough to trigger nucleation without any prior change in the local stability due to radiative cooling (not shown).

\subsection{Variation of RHi gradient at ISSR boundary}

Here we discuss the influence of the water vapour gradient at the top of the ISSR on local heating rates. Radiosonde profiles show a variety of different shapes of the 


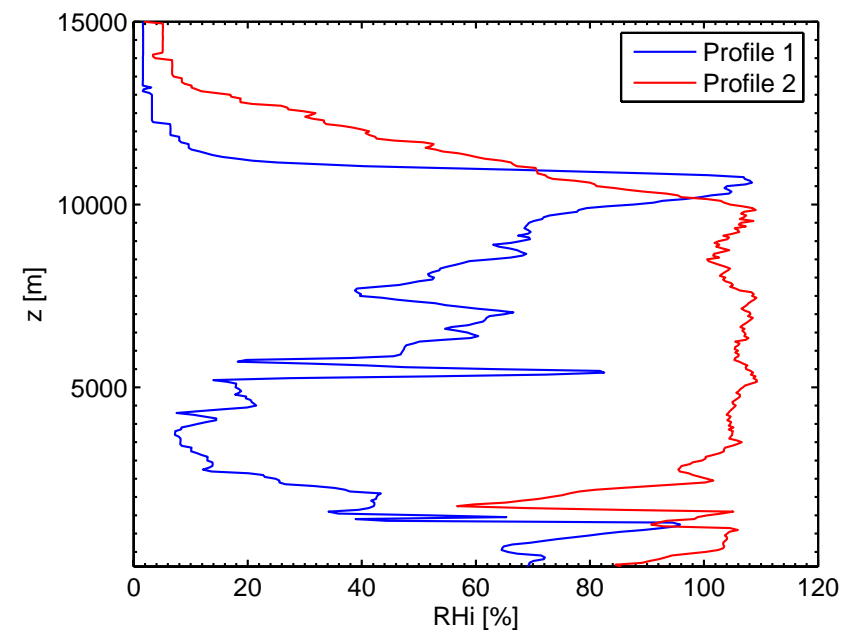

Fig. 10. Profile 1: steep upper RHi gradient (Lindenberg 1 July 2000 06:00 UTC); Profile 2: weak upper RHi gradient (Lindenberg 4 March 2001 06:00 UTC).

RHi profile in the upper troposphere. In Fig. 10, two different radiosonde profiles with different water vapor gradients are shown. We use the same setup as in the reference case simulation (maximum $\mathrm{RHi}=140 \%$ ) and increase the vertical distance in which the RHi decreases from its maximum value down to $\mathrm{RHi}=5 \%$ near the tropopause, using following values: $d z=250 / 500 / 750 / 1000 / 1500 \mathrm{~m}$, where $d z=250 \mathrm{~m}$ stands for the reference case (see Fig. 11a).

In Fig. 11b, the heating rates for the different RHi gradients can be seen. It is clear, that for weaker gradients, the cooling area is distributed over a larger vertical layer than for stronger gradients. Therefore, the maximum cooling peak is lower, resulting in a weaker destabilization of the upper layer. Thus, only the profiles with the strongest two initial RHi-gradients were able to trigger the described cirrus formation mechanism within the simulation time of $8 \mathrm{~h}$ (assuming all other parameters to be equal to the reference case). This might be a constraint upon this kind of cloud formation process. A sharp decrease of RHi at the upper boundary of the ISSR is strictly required for destabilization due to radiative cooling. One example for a sufficient strong RHi gradient is shown in Fig. 10, Profile 1.

\subsection{Variation of temperature}

Another way to change the water vapor content within the ISSR is to vary the vertical temperature profile. Using constant initial values for RHi in the ISSR implies that for an increasing temperature, the water vapor mixing ratio will increase too. This influences the local heating rates and, due to radiation, also the destabilization of the stratification. The destabilization due to radiation is faster for profiles with higher environmental temperatures and the formed cirrus has
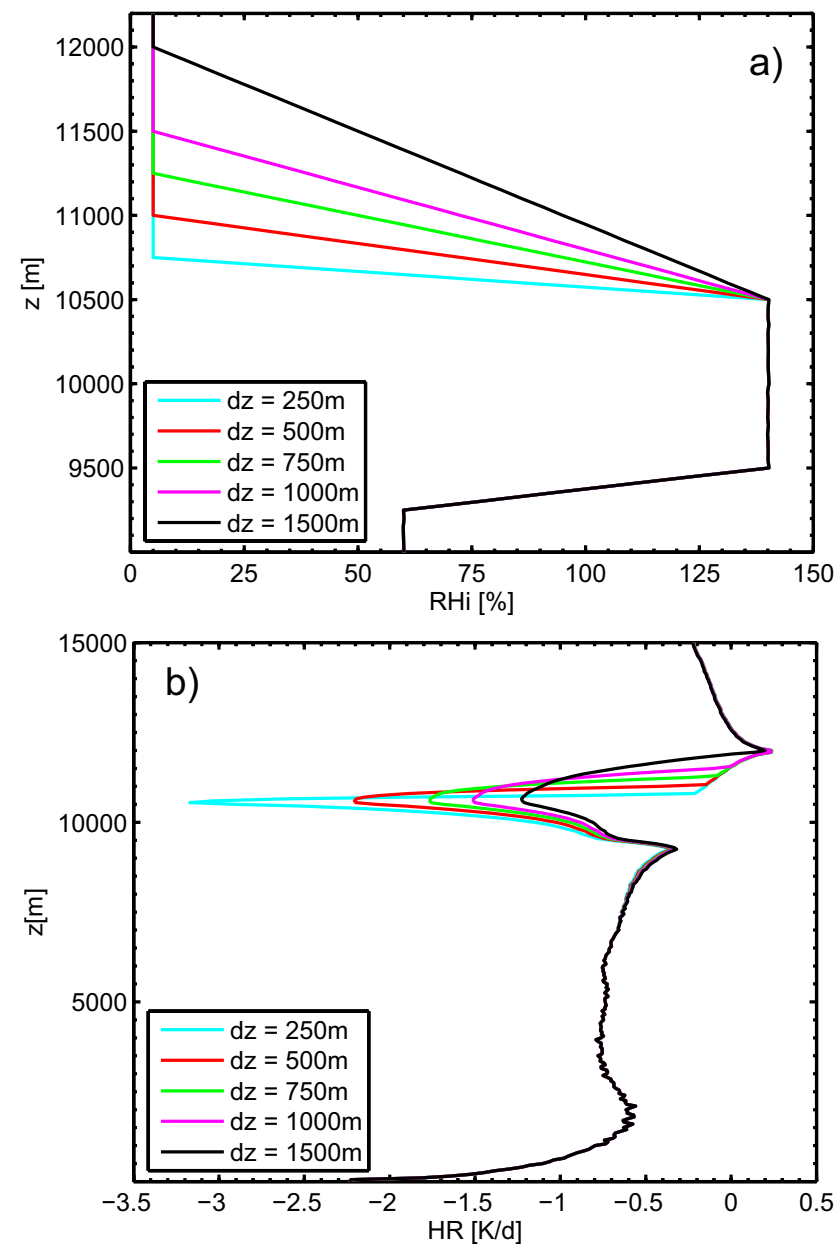

Fig. 11. (a) Vertical RHi profiles of ISSRs using different upper gradients; (b) radiative heating rates for 5 different RHi gradients (initial conditions, see (a).

a larger IWC. However, the general sensitivity of higher $\mathrm{H}_{2} \mathrm{O}$ content in the upper troposphere is shown in Sect. 4.4.

\subsection{Discussion of radiative impacts}

The variation of the potential stability has the biggest influence on the radiative properties of the formed cirrus cloud. Increasing the initial $\partial \theta / \partial z$ from 0.1 to $0.8 \mathrm{~K} / \mathrm{km}$ (i.e. $N=$ 0.0018 to $\left.0.005 \mathrm{~s}^{-1}\right)$, the maximum value of the mean optical depth (averaged for all columns for every time step) decreases from $\bar{\tau}=0.36$ to 0.05 (see Fig. 12a-c). Note that this is a mean value over the whole domain and the values for single columns can be considerably larger (the largest optical depth for a single column can be observed in case of the smallest potential stability: $\tau_{\max }=0.82$ ). The smallest changes of $\tau$ can be observed for the sensitivity study of changing initial RHi ( $\bar{\tau}=0.14$ to 0.08 ). For all cases, the calculated total outgoing radiation fluxes (the sum of shortwave 

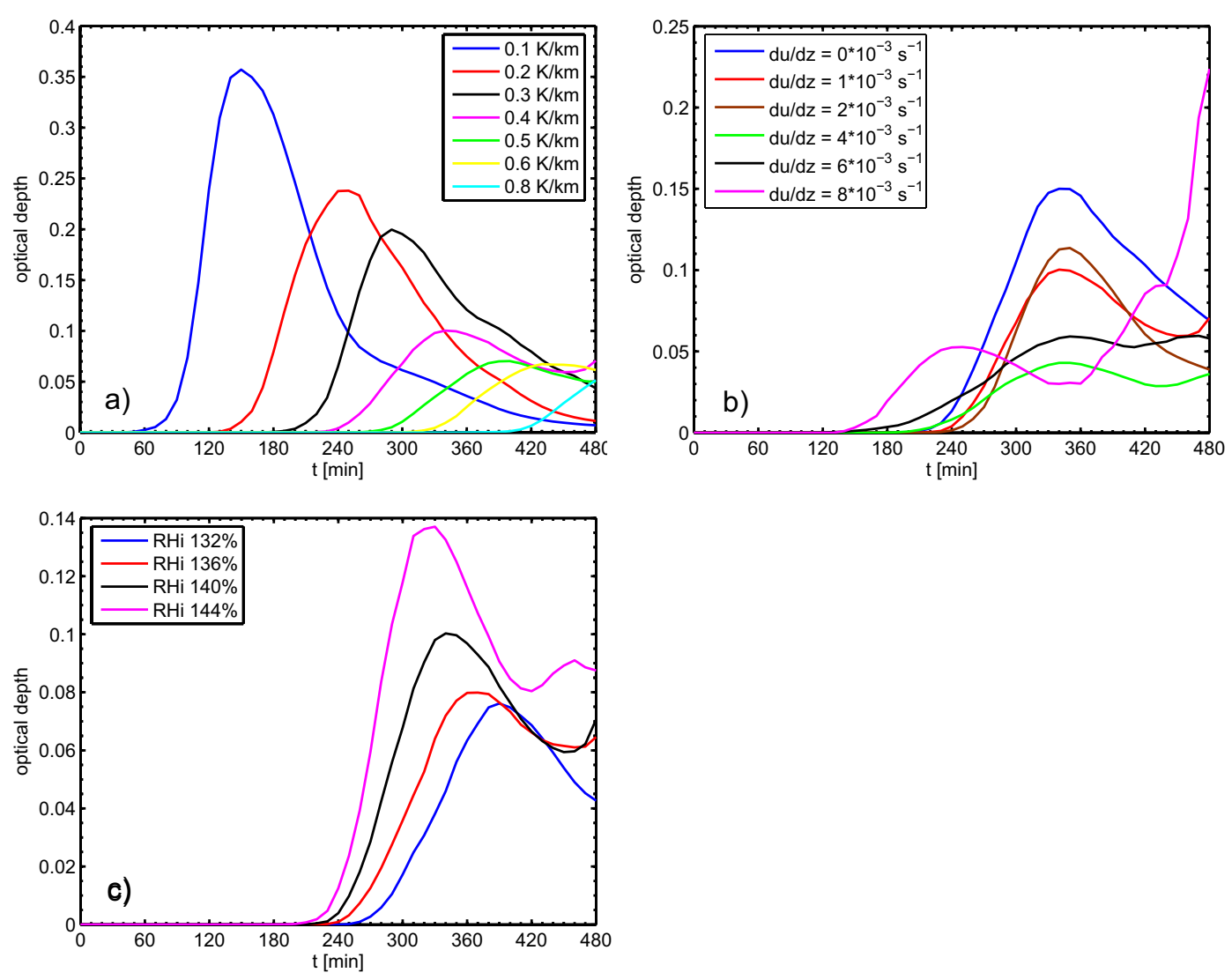

Fig. 12. Mean optical depth (as a function of time) of cirrus clouds, triggered by radiative cooling for following sensitivity studies: (a) thermal stratification; (b) dynamic stability (variation of vertical wind shear); (c) RHi, using different peak values inside the ISSR.

and longwave radiation) decrease by a certain amount after the cloud formation, i.e. the difference between the absorbed and emitted longwave radiation inside the cloud exceeds the amount of reflected shortwave radiation at the cloud top (warming scenario, see Fusina et al., 2007).

\section{Conclusions}

The nonhydrostatic, anelastic model EULAG (Prusa et al., 2008) was used with a recently developed and validated ice microphysics scheme (Spichtinger and Gierens, 2009a) and an additionally implemented fast radiative transfer code ( $\mathrm{Fu}$ et al., 1998) to investigate the influence of a superposition of radiative cooling and small eddies on cirrus formation. For this purpose, idealized profiles with high supersaturations up to $144 \%$ RHi and weak thermal stability have been used. The focus is on the multiscale aspect of cirrus formation superimposing large scale (i.e. radiative cooling) with small scale (i.e. small eddies) effects. Only the combination of these effects results in significant cloud formation.

The results can be summarized as follows: destabilization due to radiative cooling can lead to amplification of small scale eddies, which can act as an initial cloud forming mechanism. Sensitivity studies for following parameters have been performed: static and dynamic stability and the RHi within the ISSR. The values of these key factors should be between 0.1 and $0.8 \mathrm{~K} / \mathrm{km}$ for the thermal stability (i.e. the vertical gradient of the potential temperature), 132 to $144 \%$ RHi and there should be no shear instability $(\mathrm{Ri}>0.25)$.

Our investigations could answer some questions concerning the formation of cirrus clouds due to radiative cooling:

1. Cooling due to thermal emission at the top of an ISSR can destabilize an initial weak stable profile within several hours (depending on the initial stability and RHi).

2. During destabilization, the amplitude of initial small eddies increases and leads to the first nucleation of ice crystals. Supported by the subsequent latent heat release, vertical updraft velocities up to $1.6 \mathrm{~m} / \mathrm{s}$ can occur.

3. Within the first $8 \mathrm{~h}$, cirrus clouds are formed with mean ice water paths up to $8.9 \times 10^{-3} \mathrm{~kg} / \mathrm{m}^{2}$ and ice crystal number densities up to $N=350 \mathrm{~L}^{-1}$. 
4. In sensitivity studies it was shown that increasing the initial potential stability would delay the first nucleation event up to several hours and decrease the strength of the nucleation event, as we can see for IWP and $N$. Increasing the initial wind shear would lead to smaller cells, and therefore to nucleation of fewer crystals. Increasing the RHi within the ISSR amplifies the thermal emission and shortens the duration to the first nucleation event, but it has only a marginal effect on the vertical velocities. This will lead to cirrus clouds with larger IWP.

5. To obtain sufficient radiative cooling at the top of the ISSR, a sharp decrease of RHi is required.

Using a simple phase-diagram (Fig. 13) we can explain the sensitivity due to certain parameters. If the initial RHi is lower than the boundary (a), the radiative cooling would be too weak to destabilize the stratification. If it is too high (boundary (c)), the random motions due to initial temperature fluctuations would be strong enough to trigger a cloud before the profile becomes unstable. If the stability (static or dynamic) becomes too weak (boundary (b)), updrafts can be triggered spontaneously due to initial small-scale motions or induced shear-instability. If it becomes too strong (boundary (d)), the radiative cooling is again not strong enough to destabilize the profile within a certain time $(8 \mathrm{~h}$ for this simulations). At least for conditions near the boundary (b), it is very hard to distinguish which of the observed effects (e.g. destabilization due to radiative cooling, shear-instability, smallscale eddies) actually is the most important. It has to be considered that we always have a superposition of different cloud-controlling effects on different scales. It must be noted here that without radiative cooling at the top of the ISSR, there would be no cloud formation for all simulations within $8 \mathrm{~h}$. This implies that other cloud building mechanisms like frontal lifting or orographic effects (i.e. gravity waves) (e.g. Spichtinger and Gierens, 2009b; Joos et al., 2009) should not occur during the simulation time.

As a kind of textbook knowledge in the cirrus community it is usually assumed that radiation might not be important for the initial formation of cirrus clouds. The main argument is that radiative cooling would result into very low cooling rates or equivalently into vertical updraughts of the order of millimetres per second. This would lead to very thin cirrus clouds containing only a few ice crystals per litre (see e.g. Kärcher and Spichtinger, 2009). However, from the results of the present study this position might be revised under the comprehension of the discussed destabilisation process. In presence of weakly stable profiles both effects, i.e. radiative cooling and destabilisation might lead to the formation of visible cirrus clouds. On the other hand, the impact of radiation on the stability of the upper troposphere itself, discussed in a broader sense, should be an interesting topic for future research. From this point of view the role of convective cells in ice-supersaturated regions and cirrus cloud layers might be interesting in terms of cirrus cloud inhomogeneities and

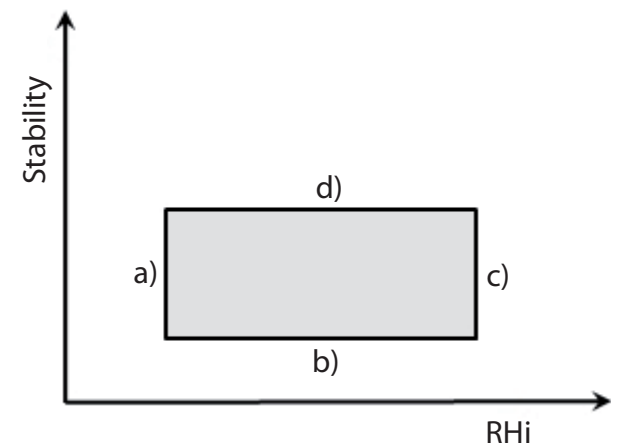

Fig. 13. Phase-diagram of possible conditions, for which thermal emission is an important cloud-building factor in dependence of the stability (statical and dynamical) and the RHi within an ISSR. The regions outside (b) and (c) accord to spontaneous cloud formation without an influence of radiation, whereas outside (a) and (d) the conditions supress any cloud formation within the simulation time.

patchiness of cirrus clouds, also in terms of the radiative impact of cirrus clouds. Finally, this could also be important for more physically based parameterisations of cirrus clouds in large-scale models, including also the macroscopic structure on the cloud scale. We could not discuss in detail the issue of frequency of occurrence of environmental conditions, which allow the radiation to have a predominant impact on the stability of the upper troposphere (and therefore be of importance for cirrus formation). The radiosonde data used originates from only one measurement site and therefore does not give an insight into global distributions. This must be investigated in future studies, using meteorological analyses and maybe also output from large-scale models in order to obtain a better overview about the importance of the described mechanism. It also remains unclear how important radiative destabilisation is, when superimposed with other large- or meso-scale processes (i.e. frontal lifting, gravity waves etc.); this will be subject of future research.

Acknowledgements. We thank the European Centre for MediumRange Weather Forecasts for computing time (special project SPCHCLAI "Cloud aerosol interactions") and Andreas Doernbrack, Ulrike Lohmann and Thomas Peter for fruitful discussions. We are grateful to Qiang $\mathrm{Fu}$ for sharing his radiation transfer scheme and Thierry Corti for help in using it. We also thank Declan O'Donnell for his help in proof-reading. This work contributes to the project "Impact of dynamics on cirrus clouds" (Grant: 200021-117700) supported by the Swiss National Science Foundation (SNSF).

Edited by: S. Buehler 


\section{References}

Birner, T.: Fine-scale structure of the extratropical tropopause region, J. Geophys. Res., 111, D04104, doi:10.1029/2005JD006301, 2006.

Clark, T. and Farley, R.: Severe downslope wind- storm calculations in two and three spatial dimensions using anelastic interactive grid nesting: A possible mechanism for gustiness, J. Atmos. Sci., 41, 329-350, 1984.

COESA: US Commission/Stand Atmosphere (Compiler): Natl. Oceanic \& Atmospheric Admin (Collaborator), Natl. Aeronautics \& Space Admin (Collaborator), United States Air Force (Collaborator), US Standard Atmosphere, NOAA, NASA, USAF, NOAA Document S/T 76-1562, 1st edn., 1976.

Dobbie, J. S., Li, J. N., and Chylek, P.: Two- and four-stream optical properties for water clouds andsolar wavelengths, J. Geophys. Res., 104, 2067-2079, 1999.

Ebert, E. E. and Curry, J. A.: A parametrization of ice cloud optical properties for climate models, J. Geophys. Res., 97, 3831-3836, 1992.

$\mathrm{Fu}, \mathrm{Q}$. A.: An accurate parameterization of the solar radiative properties of cirrus clouds for climate models, J. Climate, 9, 20582082, 1996.

Fu, Q., Yang, P., and Sun, W. B.: An accurate parameterization of the infrared radiative properties of cirrus clouds for climate models, J. Climate, 11, 2223-2237, 1998.

Fusina, F., Spichtinger, P., and Lohmann, U.: Impact of ice supersaturated regions and thin cirrus on radiation in the midlatitudes, J. Geophys. Res., 112, D24S14, doi:10.1029/2007JD008449, 2007.

Gettelman, A., Walden, V. P., Miloshevich, L. M., Roth, W. L., and Halter, B.: Relative humidity over Antarctica from radiosondes, satellites, and a general circulation model, J. Geophys. Res., 111, D09S13, doi:10.1029/2005JD006636, 2006.

Gierens, K. and Spichtinger, P.: On the size distribution of icesupersaturated regions in the upper troposphere and lowermost stratosphere, Ann. Geophys., 18, 499-504, 2000,

http://www.ann-geophys.net/18/499/2000/.

Glückauf, E.: Notes on upper air hygrometry-II: On the humidity in the stratosphere, Q. J. Roy. Meteorol. Soc., 71, 110-112, 1945.

Jensen, E. J., Toon, O. B., Tabazadeh, A., Sachse, G. W., Anderson, B. E., Chan, K. R., Twohy, C. W., Gandrud, B., Aulenbach, S. M., Heymsfield, A., Hallett, J., and Gary, B.: Ice nucleation processes in upper tropospheric wave- clouds during SUCCESS, Geophys. Res. Lett., 25, 1363-1366, 1998.

Joos, H., Spichtinger, P., and Lohmann, U.: Orographic cirrus in a future climate, Atmos. Chem. Phys., 9, 7825-7845, doi:10.5194/acp-9-7825-2009, 2009.

Kärcher, B. and Lohmann, U.: A parameterization of cirrus cloud formation: Homogeneous freezing of supercooled aerosols, J. Geophys. Res., 107, D29, AAC9-1-10, doi:10.1029/2001JD000470, 2002.
Kärcher, B. and Spichtinger, P.: Cloud-controlling Factors of Cirrus, in: Clouds in the Perturbed Climate System: Their Relationship to Energy Balance, Atmospheric Dynamics, and Precipitation, Strüngmann Forum Reports, edited by: Heintzenberg, J. and Charlson, R. J., MIT Press, 235-268, 2009.

Kajikawa, M. and Heymsfield, A.: Aggregation of ice crystals, J. Atmos. Sci., 46, 3108-3121, 1989.

Koenig, L.: Numerical modeling of ice deposition. J. Atmos. Sci., 28, 226-237, 1971.

Koop, T., Luo, B., Tsias, A., and Peter, T.: Water activity as the determinant for homogeneous ice nucleation in aqueous solutions, Nature, 406, 611-614, 2000.

Krämer, M., Schiller, C., Afchine, A., Bauer, R., Gensch, I., Mangold, A., Schlicht, S., Spelten, N., Sitnikov, N., Borrmann, S., de Reus, M., and Spichtinger, P.: Ice supersaturations and cirrus cloud crystal numbers, Atmos. Chem. Phys., 9, 3505-3522, doi:10.5194/acp-9-3505-2009, 2009.

Ovarlez, J., van Velthoven, P., Sachse, G., Vay, S., Schlager, H., and Ovarlez, H.: Comparison of water vapor measurements from POLINAT 2 with ECMWF analyses in high humidity conditions, J. Geophys. Res., 105, 3737-3744, 2000.

Prusa, J. M., Smolarkiewicz, P., and Wyszogrodzki, A.: EULAG, a computational model for multiscale flows, Computers and Fluids, 37, 1193-1207, doi:10.1016/j.compfluid.2007.12.001, 2008.

Slingo, A.: A GCM parameterization for the shortwave radiative properties of water clouds, J. Atmos. Sci., 46, 1419-1427, 1989.

Smolarkiewicz, P. and Margolin, L.: On forward- in-time differencing for fluids: an Eulerian/Semi- Lagrangian non-hydrostatic model for stratified flows, Atmosphere-Oceans, 35, 127-152, 1997.

Spichtinger, P., Gierens, K., Leiterer, U., and Dier, H.: Ice supersaturation in the tropopause region over Lindenberg, Germany, Meteorol. Z., 12, 143-156, 2003a.

Spichtinger, P., Gierens, K., and Read, W.: The global distribution of ice supersaturated regions as seen by the microwave limb sounder, Q. J. Roy. Meteorol. Soc., 129, 3391-3410, 2003 b.

Spichtinger, P. and Gierens, K. M.: Modelling of cirrus clouds Part 1a: Model description and validation, Atmos. Chem. Phys., 9, 685-706, doi:10.5194/acp-9-685-2009, 2009a.

Spichtinger, P. and Gierens, K. M.: Modelling of cirrus clouds Part 1b: Structuring cirrus clouds by dynamics, Atmos. Chem. Phys., 9, 707-719, doi:10.5194/acp-9-707-2009, 2009b.

Vay, S. A., Anderson, B. E., Jensen, E. J., Sachse, G. W., Ovarlez, J., Gregory, G. L., Nolf, S. R., Podolske, J. R., Slate, T. A., and Sorenson, C. E.: Tropospheric water vapor measurements over the North Atlantic during the Subsonic Assessment Ozone and Nitrogen Oxide Experiment (SONEX), J. Geophys. Res., 105, 3745-3756, 2000. 